\title{
Monomer-Isomerization Oligomerization of Methylenecyclohexane and Methylenecyclopentane by Acidic Catalysts
}

\author{
Toshinobu Higashimura, Toshihiro Sagane, and Hiroshi Hasegawa \\ Department of Polymer Chemistry, Kyoto University, \\ Yoshida, Sakyo-ku, Kyoto 606, Japan.
}

(Received October 22, 1980)

\begin{abstract}
On treatment with an oxo acid $\left(\mathrm{CF}_{3} \mathrm{SO}_{3} \mathrm{H}\right)$ or an oxo-acid derivative $\left(\mathrm{CH}_{3} \mathrm{COClO}_{4}\right)$ in benzene, methylenecyclohexane $(\mathrm{MCH})$ and methylenecyclopentane (MCP) isomerized quantitatively to 1-methylcyclohexene and 1-methylcyclopentene, respectively. These isomerized monomers subsequently reacted to give their oily oligomers (mainly dimers). On the other hand, in the presence of a metal halide $\left(\mathrm{AlEtCl}_{2}\right), \mathrm{MCH}$ and $\mathrm{MCP}$ scarcely isomerized and oligomers (dimers to pentamers) of $\mathrm{MCH}$ and $\mathrm{MCP}$ were produced. The catalytic behavior of $\mathrm{BF}_{3} \mathrm{OEt}_{2}$ and $\mathrm{SnCl}_{4}$ was intermediate between that of $\mathrm{CF}_{3} \mathrm{SO}_{3} \mathrm{H}$ and of $\mathrm{AlEtCl}_{2}$; that is, a portion of the monomers was isomerized before oligomerization. The structure of the dimers obtained with $\mathrm{CF}_{3} \mathrm{SO}_{3} \mathrm{H}$ and $\mathrm{AlEtCl}_{2}$ was determined by ${ }^{1} \mathrm{H}$ NMR spectroscopy, which confirmed the "monomer-isomerization" oligomerization induced specifically by oxo-acid catalysts. It was concluded that quantitative monomer isomerization precedes propagation, since a nucleophilic counterion derived from an oxo acid promotes proton elimination from protonated $\mathrm{MCH}$ or $\mathrm{MCP}$.

KEY WORDS - Cationic Oligomerization / Monomer-Isomerization /

Methylenecyclohexane / Methylenecyclopentane / 1-Methylcyclohexene / 1-

Methylcyclopentene / Oxo Acids / Metal Halides /
\end{abstract}

"Monomer-isomerization" oligomerization is a unique process in which the starting monomer isomerizes prior to propagation, to yield oligomers of the isomerized monomer. In contrast to numerous examples of monomer-isomerization polymerizations by coordinated mechanisms, ${ }^{1}$ there are only a few known instances of cationic oligomerizations with monomer isomerization.

Recently, we found ${ }^{2}$ that 2-ethyl-1,3-butadiene (2EBD) in conjunction with an oxo-acid catalyst* isomerized completely to 3-methyl-1,3-pentadiene (3MPD) prior to propagation and gave oligo (3MPD); however, a metal halide catalyst $\left(\mathrm{BF}_{3} \mathrm{OEt}_{2}\right)$ polymerized 2EBD "normally" without monomer-isomerization. The distinct difference between the oxo acid and metal halide catalysts has been explained in terms of the interaction of the counterion with the growing carbocation, ${ }^{2}$ as is

* "Oxo-acid" catalysts refer to oxygen-containing protonic acids $\left(\mathrm{CF}_{3} \mathrm{SO}_{3} \mathrm{H}, \mathrm{HClO}_{4}\right.$, etc. $)$ and their derivatives $\left(\mathrm{CH}_{3} \mathrm{COClO}_{4}\right.$, etc. $)$. discussed in detail in regard to the selective cationic dimerizations of styrenes $^{3,4}$ and 1-phenylbutadiene. $^{5}$

The present work is concerned with the cationic "monomer-isomerization" oligomerization of methylenecycloalkanes [methylenecyclopentane (MCP) and methylenecyclohexane (MCH)] which are known to isomerize to the corresponding 1methylcycloalkenes under acidic conditions. ${ }^{6,7}$ Methylenecycloalkanes (and methylcycloalkenes) also offer the possibility of synthesizing structurally interesting oligomers in which aliphatic rings are incorporated into the main chain. The cationic polymerization of these cycloalkane monomers has been investigated, ${ }^{8,9}$ but little information is available concerning monomer isomerization and the structure of the products.

Thus, we oligomerized $\mathrm{MCP}$ and $\mathrm{MCH}$ with a variety of catalysts including oxo acids and metal halides. Kinetic studies combined with product analyses have shown that the monomerisomerization of $\mathrm{MCP}$ and $\mathrm{MCH}$ depends critically 
on the nature of catalysts and solvent polarity, so that the structure of the products can be controlled by the selection of these factors.

\section{EXPERIMENTAL}

\section{Materials}

Commercial $\mathrm{MCH}(\mathrm{ICN} \cdot \mathrm{K}$ \& $\mathrm{K}$ Laboratories, Inc.), MCP (ICN Pharmaceuticals, Inc.), and 1methylcyclohexene (1-MCHE) were purified by distillation over calcium hydride. 1-methylcyclopentene (1-MCPE) was synthesized from MCP with $p$-toluenesulfonic acid in $\mathrm{CH}_{3} \mathrm{COOH}^{7}$ and was purified by distillation. The purities of these monomers were more than $99.0 \%$ as indicated by gas chromatographic analysis. Solvents [benzene and 1,2-dichloroethane $\left.\left[\left(\mathrm{CH}_{2} \mathrm{Cl}\right)_{2}\right]\right]$ and heptane were washed with aqueous $\mathrm{H}_{2} \mathrm{SO}_{4}$ and/or $\mathrm{NaOH}$ solutions, and were distilled at least twice over calcium hydride before use. Acetyl perchlorate $\left(\mathrm{AcClO}_{4}\right)$ was synthesized as described elsewhere. ${ }^{10} \mathrm{Com}$ mercial $\mathrm{CF}_{3} \mathrm{SO}_{3} \mathrm{H}$ (Sumitomo $3 \mathrm{M}$ Co., purity $\geqq$ $98 \%$ ) was used without further purification. Commercial $\mathrm{BF}_{3} \mathrm{OEt}_{2}, \quad \mathrm{AlEtCl}_{2}, \mathrm{SnCl}_{4}$, and $\mathrm{CH}_{3} \mathrm{SO}_{3} \mathrm{H}$ were purified by distillation under reduced or atmospheric pressure.

\section{Procedures}

Oligomerization was carried out in a baked Erlenmeyer flask equipped with a three-way stopcock under a dry nitrogen atmosphere. The reaction was initiated by the addition of a catalyst solution into a monomer solution containing heptane as the internal standard for gas chromatography. In this procedure, the concentration of water in the reaction mixture was smaller than $0.4 \mathrm{mmoll}^{-1}$. Water (half the molar quantity of the catalyst) was added as a cocatalyst for reactions catalyzed by metal halides in benzene. The reaction was terminated by the addition of methanol containing a small amount of aqueous ammonia. The extent of the monomer consumption and isomerization was determined by gas chromatography.

The quenched reaction solution was washed with water to remove the catalyst residue, and the products were isolated by evaporation of volatiles under reduced pressure.

The molecular weight distribution was measured by high-performance liquid chromatography (HLC; JASCO-FLC-A700, polystyrene gel JSP 101, col- umn: $7.2 \mathrm{~mm} \phi=500 \mathrm{~mm}$ for analysis; 21.5 $\mathrm{mm} \phi \times 500 \mathrm{~mm}$ for separation, $\mathrm{CHCl}_{3}$ solution, refractive index detector). The structure of the products was determined by ${ }^{1} \mathrm{H}$ nuclear magnetic resonance (NMR) (60 MHz; JEOL-MH-60, in $\mathrm{CCl}_{4}$ ) and infrared spectra (IR) (Shimadzu IR 27G) spectroscopy at room temperature.

\section{RESULTS AND DISCUSSION}

\section{Monomer-Isomerization Oligomerization by Oxo Acids}

The oligomerization of $\mathrm{MCH}$ and $\mathrm{MCP}$ was carried out with $\mathrm{CF}_{3} \mathrm{SO}_{3} \mathrm{H}$ in benzene at $50^{\circ} \mathrm{C}$. As shown by the full line in Figure 1, both monomers disappeared completely within a few minutes. Gaschromatographic analysis of the reaction mixtures indicated that $\mathrm{MCP}$ and $\mathrm{MCH}$ were converted quantitatively into other low-molecular-weight compounds which subsequently underwent slow oligomerizations to yield oily materials (dashed lines in Figure 1). These new compounds were identified as 1-methylcyclohexene (1-MCHE) for $\mathrm{MCH}$ and 1-methylcyclopentene (1-MCPE) for MCP by comparing their ${ }^{1} \mathrm{H}$ NMR spectra with those of authentic samples. Thus, $\mathrm{CF}_{3} \mathrm{SO}_{3} \mathrm{H}$ induced monomer-isomerization oligomerizations of MCP and MCH in benzene. Similar results were obtained with other oxo-acid catalysts, such as $\mathrm{AcClO}_{4}$ and $\mathrm{CH}_{3} \mathrm{SO}_{3} \mathrm{H}$.

Monomer isomerization with $\mathrm{CF}_{3} \mathrm{SO}_{3} \mathrm{H}$ was also observed at a lower temperature (at $0^{\circ} \mathrm{C}$ in benzene) and in a polar solvent (in 1,2-dichloroethane at $\left.50^{\circ} \mathrm{C}\right)$.

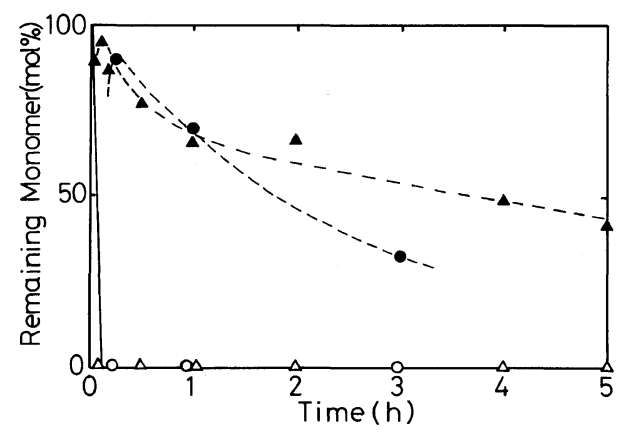

Figure 1. Residual monomer concentration as a function of time in the "monomer-isomerization" oligomerization of $\mathrm{MCH}$ and $\mathrm{MCP}$ with $\mathrm{CF}_{3} \mathrm{SO}_{3} \mathrm{H}$ in benzene at

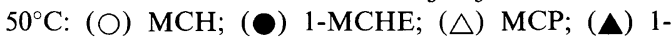
MCPE. $[\mathrm{MCH}]_{0}=[\mathrm{MCP}]_{0}=0.50 \mathrm{M} ;[\mathrm{C}]_{0}=5.0 \mathrm{mM}$. 


\section{Monomer-Isomerization Oligomerization by Metal Halides}

Figure 2 shows the time course of the oligomerization of $\mathrm{MCH}$ with various metal halides in benzene at $50^{\circ} \mathrm{C}$. The extent of monomerisomerization depended sharply on the type of metal halides. The $\mathrm{BF}_{3} \mathrm{OEt}_{2}$-catalyzed oligomerization was accompanied by quantitative monomer isomerization before propagation, as in the oligomerizations by oxo acids. But with $\mathrm{AlEtCl}_{2}$ catalyst, $\mathrm{MCH}$ oligomerized rapidly and the isomerized monomer (1-MCHE) could scarcely be observed $\left(<5 \%\right.$ of $\left.[\mathrm{MCH}]_{0}\right) . \mathrm{SnCl}_{4}$ showed an intermediate behavior as catalyst, resulting in the oligomerization of $\mathrm{MCH}$ and its concurrent slow isomerization to 1-MCHE.

In the oligomerization of $\mathrm{MCP}$ in benzene (Figure 3), both $\mathrm{BF}_{3} \mathrm{OEt}_{2}$ and $\mathrm{SnCl}_{4}$ quantitatively induced $\mathrm{MCP}$ isomerization to 1-MCPE prior to propagation. With $\mathrm{AlEtCl}_{2}$, however, the amount of the isomerized monomer leveled off at $c a .25 \%$ $[\mathrm{MCP}]_{0}$ and did not decrease with time. The reactivity of 1-MCPE was confirmed to be much smaller than that of MCP in the homo- and copolymerizations of these monomers by $\mathrm{AlEtCl}_{2}$.

MCP was found to be more prone to isomerize than $\mathrm{MCH}$ under the same conditions, as indicated by a comparison of the data in Figures 2 and 3 for $\mathrm{AlEtCl}_{2}$ or $\mathrm{SnCl}_{4}$. This is because the strain of a fivemembered ring (MCP) is greater than that of a sixmembered ring $(\mathrm{MCH})$.

Results similar to the above were obtained for $\mathrm{MCP}$ and $\mathrm{MCH}$ at lower temperatures or in a polar solvent (1,2-dichloroethane). It should be mentioned that with $\mathrm{AlEtCl}_{2}$, no isomerization of $\mathrm{MCH}$ occurred at all in 1,2-dichloroethane at 0 $50^{\circ} \mathrm{C}$ ( $c f$. Figure 2).

Nature of Catalysts and Monomer Isomerization of Methylenecycloalkanes

The results described above demonstrate that the extent of the monomer isomerization of MCP and $\mathrm{MCH}$ depends strongly on the type of catalysts. Isomerization decreased in the following order:

$$
100 \% \sim \text { oxo acids } \gtrsim \mathrm{BF}_{3} \mathrm{OEt}_{2}>\mathrm{SnCl}_{4} \gg \mathrm{AlEtCl}_{2} \text {. }
$$

All the oxo-acid catalysts $\left(\mathrm{CF}_{3} \mathrm{SO}_{3} \mathrm{H}, \mathrm{AcClO}_{4}\right.$, etc. $)$ employed induced a quantitative and rapid monomer isomerization. A similar result has been

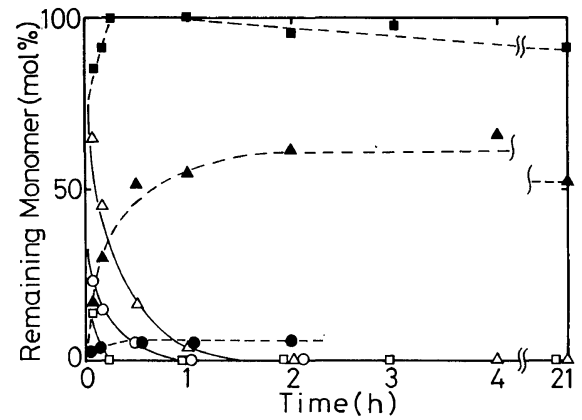

Figure 2. Oligomerization of $\mathrm{MCH}\left([\mathrm{M}]_{0}=0.50 \mathrm{M}\right)$ by metal halides in benzene at $50^{\circ} \mathrm{C}$ : (-) consumption of $\mathrm{MCH} ;(---)$ concurrent formation and consumption of 1-MCHE. Catalyst $(10.0 \mathrm{mM}):(\square, \boldsymbol{\square}) \mathrm{BF}_{3} \mathrm{OEt}_{2} ;(\triangle$, A) $\mathrm{SnCl}_{4} ;\left(\mathrm{O}\right.$, O) $\mathrm{AlEtCl}_{2}$. Cocatalyst: $\mathrm{H}_{2} \mathrm{O}, 5.0 \mathrm{mM}$.

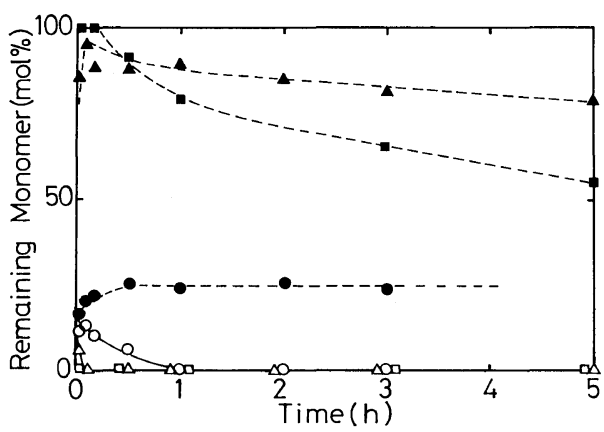

Figure 3. Oligomerization of $\mathrm{MCP}\left([\mathrm{M}]_{0}=0.50 \mathrm{M}\right)$ by metal halides in benzene at $50^{\circ} \mathrm{C}:(-)$ consumption of $\mathrm{MCP}$; (----) concurrent formation and consumption of 1-MCPE. Catalyst $(10.0 \mathrm{mM}):(\square, \square) \mathrm{BF}_{3} \mathrm{OEt}_{2} ;(\triangle$, A) $\mathrm{SnCl}_{4} ;\left(\bigcirc\right.$, O) $\mathrm{AlEtCl}_{2}$. Cocatalyst: $\mathrm{H}_{2} \mathrm{O}, 5.0 \mathrm{mM}$.

obtained in the monomer-isomerization oligomerization of $2 \mathrm{EBD} .^{2}$

The isomerization of a methylenecycloalkane to the corresponding 1-methylcycloalkene proceeds via proton elimination from the protonated form (monomer cation) of the methylenecycloalkane. The proton elimination is facilitated by a nucleophilic counterion that interacts strongly with the monomer cation and its $\beta$-hydrogen. Namely, the more nucleophilic the counterion is, the more the monomer isomerization will be promoted.

The above argument in turn suggests that the extent of monomer isomerization is a measure of the nucleophilicity of the counterion derived from a catalyst. The greatest extent of isomerization $(100 \%)$ obtained with oxo-acid catalysts support this expectation, since, as pointed out previously, ${ }^{3,4}$ 
the counterions formed from oxo acids possess nucleophilic oxygen atoms which interact strongly with both carbocations and its $\beta$-hydrogens. The observed order (eq 1) for metal halides is of interest in view of the absence of a reliable experimental measure of the nucleophilicity of their counterions. Equation 1 suggests that, for metal halides, the nucleophilicity of the counterions is determined primarily by their ionic radii.

\section{Molecular Weight Distribution of the Oligomers}

Figure 4 shows the molecular weight distribution (MWD) of the oligomers obtained from $\mathrm{MCH}$ and MCP by various catalysts in benzene at $50^{\circ} \mathrm{C}$. All these samples were recovered after the initially fed $\mathrm{MCP}$ or $\mathrm{MCH}$ had been consumed completely by oligomerization and/or isomerization. Therefore, according to the time-course data (Figures 1, 2, and 3 ), the products with $\mathrm{AlEtCl}_{2}$ should be oligomers of $\mathrm{MCP}$ or $\mathrm{MCH}$, while those with $\mathrm{CF}_{3} \mathrm{SO}_{3} \mathrm{H}$ and $\mathrm{BF}_{3} \mathrm{OEt}_{2}$ should be oligomers of the isomerized monomers (1-MCPE and 1-MCHE). This was confirmed by the ${ }^{1} \mathrm{H}$ NMR analysis described later.

In benzene 1-MCPE and 1-MCHE (with $\mathrm{CF}_{3} \mathrm{SO}_{3} \mathrm{H}$ and $\mathrm{BF}_{3} \mathrm{OEt}_{2}$ ) gave mainly dimers, whereas $\mathrm{MCP}$ and $\mathrm{MCH}$ (with $\mathrm{AlEtCl}_{2}$ ) yielded mixtures of dimers and trimers together with higher oligomers. The higher yields of dimers for 1$\mathrm{MCPE}$ and 1-MCHE are probably due to the greater steric hindrance in these trisubstituted olefins.

The effect of reaction parameters on the MWD of the oligomers produced from $\mathrm{MCP}$ with $\mathrm{CF}_{3} \mathrm{SO}_{3} \mathrm{H}$ and $\mathrm{AlEtCl}_{2}$ are shown in Figure 5. The molecular weight of the products increased with an increase in solvent polarity from benzene to 1,2-dichloroethane at $50^{\circ} \mathrm{C}$. In particular, the product with $\mathrm{CF}_{3} \mathrm{SO}_{3} \mathrm{H}$ consisted of $c a .50 \mathrm{wt} \%$ of oligomers with the degree of polymerization (DP) $\sim 10$. The MWD of the oligomers produced at $0^{\circ} \mathrm{C}$ was similar to that at $50^{\circ} \mathrm{C}$ under otherwise the same conditions. Thus, the solvent polarity is more effective in controlling the molecular weight than the reaction temperature.

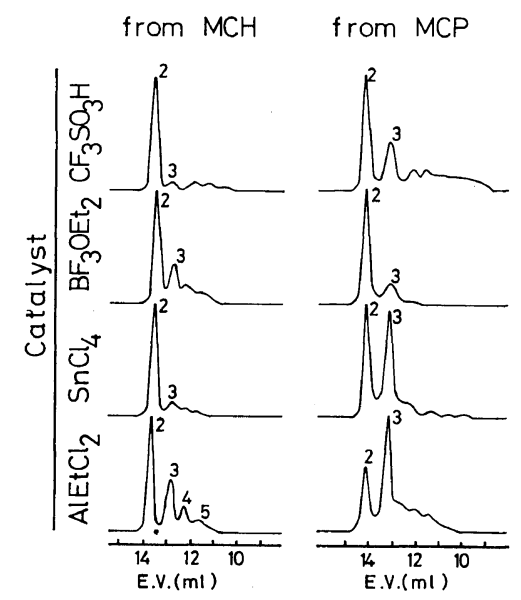

Figure 4. Effect of catalysts on the MWD of oligomers obtained from $\mathrm{MCH}$ and $\mathrm{MCP}$ in benzene at $50^{\circ} \mathrm{C}$ : $[\mathrm{M}]_{0}=0.50 \mathrm{M} ;\left[\mathrm{CF}_{3} \mathrm{SO}_{3} \mathrm{H}\right]_{0}=5.0 \mathrm{mM} ;[\text { metal halide }]_{0}=$ $10.0 \mathrm{mM}\left(\left[\mathrm{H}_{2} \mathrm{O}\right]_{0}=5.0 \mathrm{mM}\right)$; conversions of $\mathrm{MCH}$ and MCP, $100 \%(t=5 \sim 120 \mathrm{~min})$. Numbers indicate the degree of polymerization.

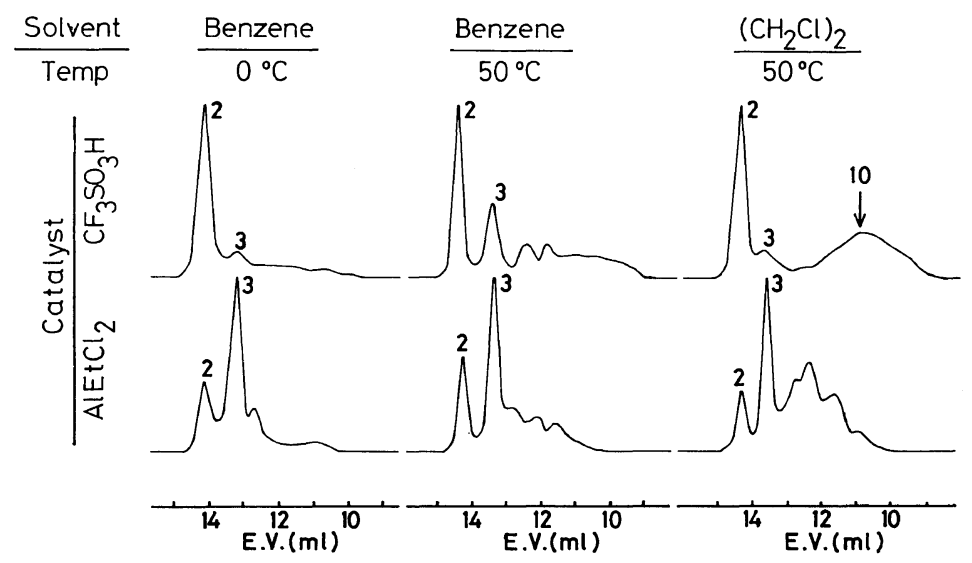

Figure 5. Effect of temperature and solvent on the MWD of oligomers obtained from MCP: $[\mathrm{M}]_{0}=0.50 \mathrm{M},\left[\mathrm{CF}_{3} \mathrm{SO}_{3} \mathrm{H}\right]_{0}=5.0 \mathrm{mM},\left[\mathrm{AlEtCl}_{2}\right]_{0}=10.0 \mathrm{mM}\left(\left[\mathrm{H}_{2} \mathrm{O}\right]_{0}=5.0 \mathrm{mM}\right) ;$ conversions of $\mathrm{MCP}$, $100 \%(t=1 \sim 60 \mathrm{~min})$. Numbers indicate the degree of polymerization. 


\section{Structure of the Dimers}

The dimers obtained from MCP in benzene at $50^{\circ} \mathrm{C}$ ( $c f$. Figure 4) were separated from the crude products by preparative HLC and analyzed by ${ }^{1} \mathrm{H}$ NMR spectroscopy. Figure 6 shows the NMR spectra of the dimers produced by $\mathrm{CF}_{3} \mathrm{SO}_{3} \mathrm{H}$ (A) and $\mathrm{AlEtCl}_{2}$ (B).

Spectrum (A) agreed with that of 1-MCPE dimer prepared separately from an authentic sample of 1MCPE with $\mathrm{CF}_{3} \mathrm{SO}_{3} \mathrm{H}$. 1-MCPE did not isomerize to $\mathrm{MCP}$ under the conditions employed. Therefore the dimer obtained by $\mathrm{CF}_{3} \mathrm{SO}_{3} \mathrm{H}$ is that of 1-MCPE (the isomerized monomer for MCP). Equation 2 makes evident the pathway for the formation of 1MCPE dimer together with its possible structures
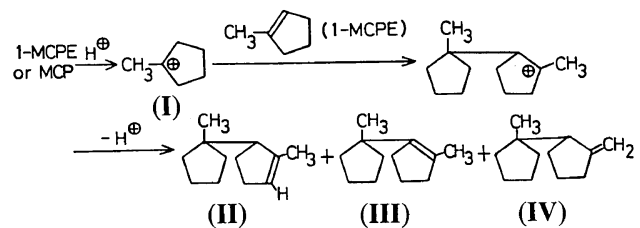

(II-IV). Structure IV is least likely since no vinylidene $\left(\mathrm{CH}_{2}=\mathrm{C}^{\prime}\right)$ absorption could be detected in the IR spectrum of the dimer. Figure 6(A), on the other hand, is consistent with structures II and III. The two singlets (a) (0.85 ppm) and (b) (1.03 ppm) in the aliphatic methyl region are assignable to the end methyl protons of dimers II and III, respectively. ${ }^{11}$ Other peak assignments are indicated in Figure 6. The dimer should thus be a mixture of dimers II and III.

Spectrum (B) for the dimer obtained by $\mathrm{AlEtCl}_{2}$ was found to be different from that of the 1-MCPE dimer (A). Since no isomerization of $\mathrm{MCP}$ was observed with $\mathrm{AlEtCl}_{2}$, the dimer (B) should be that of MCP itself as shown in eq 3. Although two structures (V and $\mathbf{V I})$ are possible, only one methyl signal (f, $0.91 \mathrm{ppm}$ ) was observed in Spectrum (B). The ratio of the methylene protons attached to $\mathrm{C}=\mathrm{C}$ (peak $\mathrm{h}, 1.7 \sim 2.5 \mathrm{ppm}$ ) to other methylene

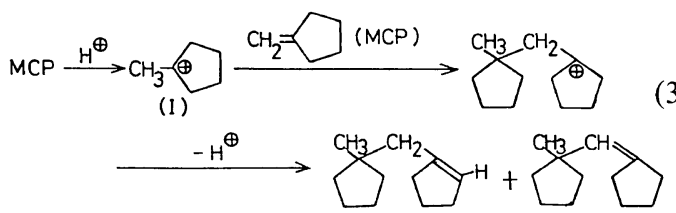

(V)

(VI) protons (peak g, 1.2 1.7 ppm) was 6.0 6.6:10,
(II) :

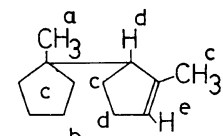

(III) :

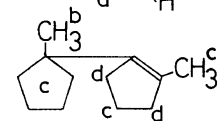

(A)

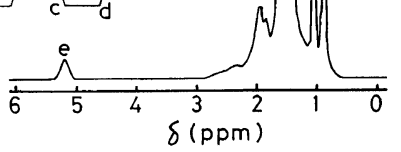

(V):

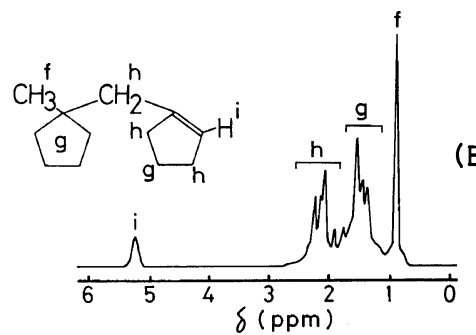

(B)

Figure 6. ${ }^{1} \mathrm{H}$ NMR spectra of dimers obtained from MCP with $\mathrm{CF}_{3} \mathrm{SO}_{3} \mathrm{H}(\mathrm{A})$ and $\mathrm{AlEtCl}_{2}$ (B) in benzene at $50^{\circ} \mathrm{C}:[\mathrm{M}]_{0}=0.50 \mathrm{M},\left[\mathrm{CF}_{3} \mathrm{SO}_{3} \mathrm{H}\right]_{0}=5.0 \mathrm{mM},\left[\mathrm{AlEtCl}_{2}\right]_{0}$ $=10.0 \mathrm{mM}\left(\left[\mathrm{H}_{2} \mathrm{O}\right]_{0}=5.0 \mathrm{mM}\right)$. Both samples were separated from the products shown in Figure 5.

which agrees closely with the theoretical value (6:10) for dimer $\mathbf{V}(4: 12$ for VI). Therefore, the dimer produced with $\mathrm{AlEtCl}_{2}$ was mainly $\mathbf{V}$.

Similar structures were found for the reaction of $\mathrm{MCH}$ with $\mathrm{CF}_{3} \mathrm{SO}_{3} \mathrm{H}$ and $\mathrm{AlEtCl}_{2}$. In the ${ }^{1} \mathrm{H} \mathrm{NMR}$ spectrum of the dimer produced from $\mathrm{MCH}$ by $\mathrm{CF}_{3} \mathrm{SO}_{3} \mathrm{H}$, two singlet signals $(0.69 \mathrm{ppm}$ and 0.90 $\mathrm{ppm}$ ) of methyl protons were observed, and in that by $\mathrm{AlEtCl}_{2}$ one singlet signal $(0.83 \mathrm{ppm})$ was observed.

\section{Conclusion}

The most important conclusion in this work is summarized in Scheme I.

With $\mathrm{AlEtCl}_{2}$ catalyst, the methylenecycloalkanes were oligomerized to yield dimers in benzene or higher oligomers (dimers to decamers) in 1,2dichloroethane, and monomer isomerization was scarcely observed (Path 1). On the other hand, $\mathrm{CF}_{3} \mathrm{SO}_{3} \mathrm{H}$ (or $\mathrm{BF}_{3} \mathrm{OEt}_{2}$ ) catalyst induced the complete isomerization of the methylenecycloalkanes to the corresponding 1-methylcycloalkenes, and the latter monomers led to the formation of dimers in benzene or oligomers ( $\sim$ decamers) in 1,2-dichloroethane (path 2). 


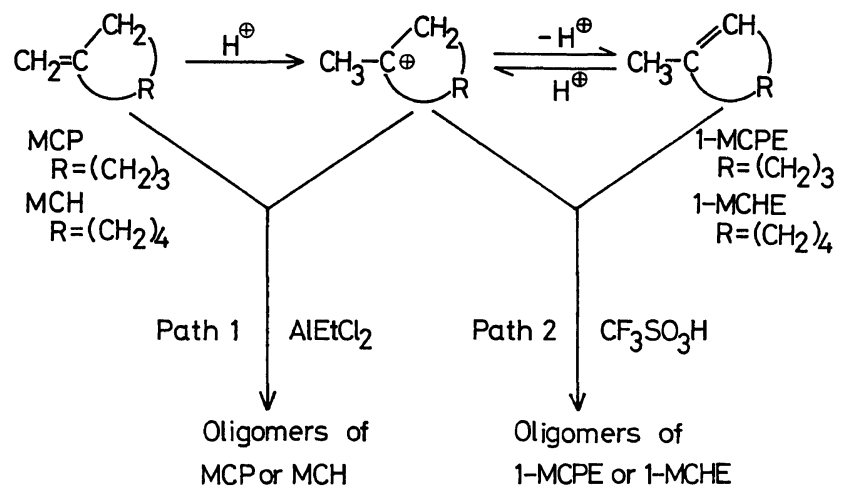

Scheme I.

Acknowledgement. The authors wish to thank Dr. M. Sawamoto for his helpful comments.

\section{REFERENCES}

1. J. P. Kennedy and T. Otsu, Adv. Polym. Sci., 7, 369 (1970).

2. T. Higashimura and H. Hasegawa, J. Polym. Sci., Polym. Chem. Ed., 17, 2439 (1979).

3. (a) M. Sawamoto, T. Masuda, H. Nishii, and T. Higashimura, J. Polym. Sci., Polym. Lett. Ed., 13, 279 (1975); (b) T. Higashimura and H. Nishii, $J$. Polym. Sci., Polym. Chem. Ed., 15, 329 (1977); (c) H. Nishii and T. Higashimura, J. Polym. Sci., Polym. Chem. Ed., 15, 1179 (1977).

4. T. Higashimura, M. Hiza, and H. Hasegawa,
Macromolecules, 12, 217 (1979).

5. T. Higashimura and H. Hasegawa, J. Polym. Sci., Polym. Chem. Ed., 17, 59 (1979).

6. J. Herling, J. Shabtai, and E. Gil-Av, J. Am. Chem. Soc., 87, 4107 (1965).

7. A. C. Cope, D. Ambros, E. Ciganek, C. F. Howell, and Z. Jacura, J. Am. Chem. Soc., 82, 1750 (1960).

8. O. E. Van Lohuizen and K. S. De Vries, J. Polym. Sci., C, No. 16, 3943 (1968).

9. W. J. Roberts and A. R. Day, J. Am. Chem. Soc., 72, 1226 (1950).

10. T. Masuda and T. Higashimura, J. Macromol. Sci., Chem., A5, 549 (1971).

11. R. M. Silberstein, G. C. Bassler, and T. C. Morrill, "Spectrometric Identification of Organic Compounds," 3rd ed, John Wiley \& Sons, New York, N.Y., 1974, pp 212 and 213. 